\title{
CMV encephalitis in an immune-competent patient
}

\author{
Sarah Micallef, ${ }_{1}^{1}$ Ruth Galea ${ }^{2}$
}

${ }^{1}$ Department of Medicine, Mater Dei Hospital, Msida, Malta ${ }^{2}$ Department of Neurosciences, Mater Dei Hospital, Msida, Malta

Correspondence to Dr Sarah Micallef, sarah.a.micallef@gov.mt

Accepted 16 June 2018

Check for updates

(c) BMJ Publishing Group Limited . No commercial re-use. See rights and permissions. Published by BMJ.

To cite: Micallef $S$, Galea R. BMJ Case Rep Published Online First: [please include Day Month Year]. doi:10.1136/bcr-2018224740

\section{SUMMARY}

After being admitted to hospital with atypical chest pain, a 61-year-old woman was noted to become lethargic and confused. She also developed global dysphasia. MRI was suggestive of encephalitis, and lumbar puncture was positive for cytomegalovirus (CMV) PCR. The patient was treated with intravenous ganciclovir and subsequent oral valganciclovir and she gradually made a reasonable recovery. While this infection is usually closely linked to immunosuppression, the patient was found to be HIV negative, and was not on any immunosuppressive therapy. Going through the patient's medical history revealed two possible risk factors which might have led to the development of CMV encephalitis: immunosuppression secondary to underlying poorly controlled diabetes mellitus; and previous admission to the intensive care unit which might have lead to CMV reactivation.

\section{BACKGROUND}

Cytomegalovirus (CMV) is a rare cause of viral encephalitis in adults, and typically affects immune-compromised patients. Few case reports describe CMV encephalitis in immune-competent patients.

\section{CASE PRESENTATION}

A 61-year-old Caucasian woman with multiple comorbidites presented to hospital with atypical chest pain. Her medical history included uncontrolled type 2 diabetes mellitus, hypertension, ischaemic heart disease, congestive heart failure, paroxysmal atrial fibrillation, asthma, depression and mild renal impairment. The patient had also had two admissions for left malignant necrotising otitis externa (NOE) over the previous 4 months, which had required admission to the intensive care unit due to cardiac complications.

A few days into her admission, the patient complained of persistent left ear pain. Examination revealed a swollen and hyperaemic left external auditory meatus and the patient was started on oral ciprofloxacin in view of a suspected early recurrence of NOE.

The patient was also noted to become increasingly lethargic. Parameters, including glucose levels and temperature, were normal. Polypharmacy was initially suspected as a possible underlying cause, and the patient was reviewed by the psychiatric team. Despite treatment adjustment, the lethargy persisted, and the patient became increasingly confused and developed word finding difficulties. Eventually, the patient developed global dysphasia.
Encephalopathy was suspected, and a neurology review was therefore sought. A full neurological examination could not be performed, as the patient was unable to follow simple commands.

\section{INVESTIGATIONS}

MRI showed diffuse cortical swelling in the left occipital and temporal regions on fluid-attenuated inversion recovery (FLAIR) and T2 sequences, affecting the posterior division of the left middle cerebral and posterior cerebral territory (figure 1). Effacement of the adjacent sulci and restricted diffusion was also noted, this being consistent with encephalitis. Lumbar puncture showed clear cerebrospinal fluid (CSF) at an opening pressure of $20 \mathrm{~cm}$ of water. Investigations showed an acellular CSF with mildly raised proteins $(556 \mathrm{mg} / \mathrm{L})$ on CSF biochemistry. CSF glucose levels were over $50 \%$ of serum glucose levels. CSF microscopy and culture were also performed and eventually also came back negative.

CSF viral PCR was also performed and CMV antigen was detected at 2857 copies $/ \mathrm{mL}$. Herpes simplex virus (HSV), Epstein-Barr virus (EBV) and varicella zoster (VZV) antigens were not detected by PCR. A concurrent full blood count showed a normal white cell and neutrophil count, a haemoglobin of $11.3 \mathrm{~g} / \mathrm{dL}$ and elevated platelets $\left(544 \times 10^{\wedge} 9 / \mathrm{L}\right)$. C reactive protein was $12.5 \mathrm{mg} / \mathrm{L}$ (down from $47.1 \mathrm{mg} / \mathrm{L}$ on admission, normal range 0-10 mg/L). Serum CMV-PCR was negative. CMV serology was positive for anti-CMV IgG antibodies, while anti-CMV IgM antibodies were reported as 'indefinite'.

Given the clinical picture of an encephalopathy, the findings on MRI and a positive CMV PCR in the CSF, the working diagnosis was that of CMV encephalitis. While the diagnosis of a bacterial cerebritis secondary to an underlying recurrence of NOE was entertained, the negative CSF microscopy and cultures and normal CSF cell count and biochemistry made this diagnosis far less likely. Moreover, the patient had already been started on oral fluoroquinolones in view of a suspicion of a recurrence of NOE, yet despite this her neurological condition worsened. In view of the suspected diagnosis of CMV encephalitis, the patient subsequently underwent investigations for underlying immunosuppression and underwent HIV and hepatitis screening, which came back negative.

\section{TREATMENT}

The patient was started on intravenous ganciclovir $350 \mathrm{mg}$ two times a day for 14 days. The patient gradually improved, becoming more alert and 


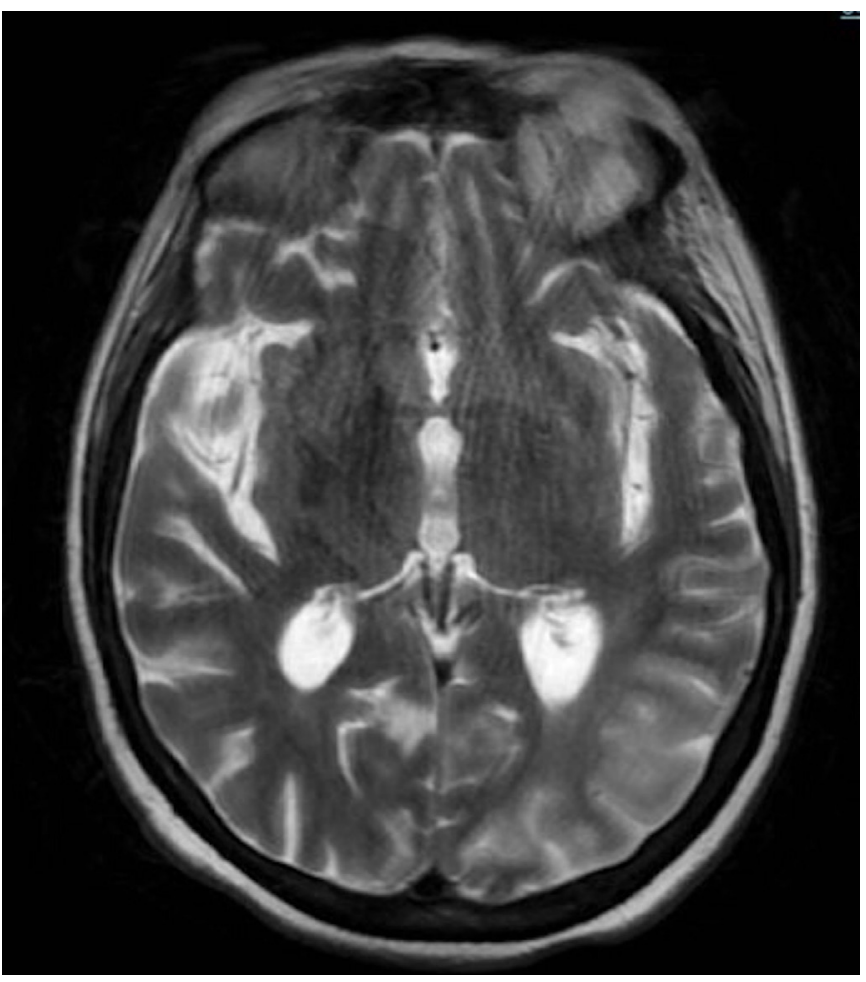

Figure 1 MRI T2 sequence showing diffuse cortical swelling in the left occipital and temporal regions affecting the posterior division of the left middle cerebral and posterior cerebral territory with the effacement of the sulci.

oriented. She was then switched to oral valganciclovir $900 \mathrm{mg}$ two times a day for a further 3 months.

\section{OUTCOME AND FOLLOW-UP}

Repeat MRI done 3 weeks after starting the patient on ganciclovir showed a decrease in the extent of the oedema in the left parietal and temporal lobes when compared with the previous scan (figure 2). The associated diffusion restriction has also decreased. The patient remained well, and was transferred to a rehabilitation hospital soon after. Repeat lumbar puncture was performed 6 weeks after starting treatment with intravenous ganciclovir. CMV DNA was not detected by PCR. Unfortunately, the patient was left with residual moderate cognitive impairment.

\section{DISCUSSION}

CMV is a double-stranded DNA virus, and is part of the Herpesviridae family. It is a ubiquitous virus that infects almost all individuals, and around $40 \%-100 \%$ of healthy individuals have positive serology (CMV antibodies). Primary infection is usually asymptomatic in immune-competent hosts, but may produce mild influenza-like symptoms such as fever, pharyngitis and lymphadenopathy. CMV is, however, an important cause of morbidity and mortality in immunocompromised patients, such as patients with HIV/AIDS, those on immunosuppressant therapy and recipients of solid organ transplants or haematopoietic stem cell transplants.

CMV disease can manifest in a variety of ways; it may involve the central and peripheral nervous system, the gastrointestinal system, and may cause pneumonitis and hepatitis. It may also present as an acute systemic febrile illness with fever, malaise, rash and arthralgia . ${ }^{1}$
CMV encephalitis is one of the rarer manifestations of CMV infections and may present in a variety of ways. It may be asymptomatic, but may present with confusion, cognitive decline, neurological signs and cranial nerve palsies. Confirmed diagnosis is achieved by viral PCR. MRI typically shows non-specific increased T2/FLAIR signal affecting cerebral white matter. Viral infections of the central nervous system can be caused by a number of viral pathogens. In one study carried out on elderly patients above 65 years of age, Parisi et al showed that CMV was implicated in only $1.5 \%$ of cases of viral encephalitis. ${ }^{2}$ Other, more commonly implicated viruses included HSV, VZV, EBV and human herpes viruses 6 and 7. Treatment guidelines for CMV encephalitis in immunocompromised hosts suggest combination therapy with ganciclovir and foscarnet as first line therapy; monotherapy with either drug is an alternative choice. ${ }^{3}$

In most cases, CMV encephalitis occurs in patients who are immunocompromised, very often patients infected with HIV/ AIDS. $^{4}$ CMV central nervous system involvement is rare and constitutes less than $1 \%$ of CMV infections in these patients. However, such infections are severe, and may have up to $100 \%$ mortality if left untreated. ${ }^{4}$ Conversely, CMV encephalitis in immune-competent humans is very rare and only a handful of cases have been reported. ${ }^{5-7}$

So why would a patient, with no obvious cause for immunosuppression, develop such a rare disease? Our patient was HIV negative and was not on any immunosuppressant medications or systemic steroids. Two possible explanations may shed some light with respect to answering this question, and it is this that makes this case an important learning point.

One possible risk factor which led to immunosuppression in this case could be poorly controlled diabetes mellitus; her HbAi1c had been recorded at $95.0 \mathrm{mmol} / \mathrm{mol}$ (normal range $28-46 \mathrm{mmol} / \mathrm{mol}$ ) during the past year. Over the previous 8

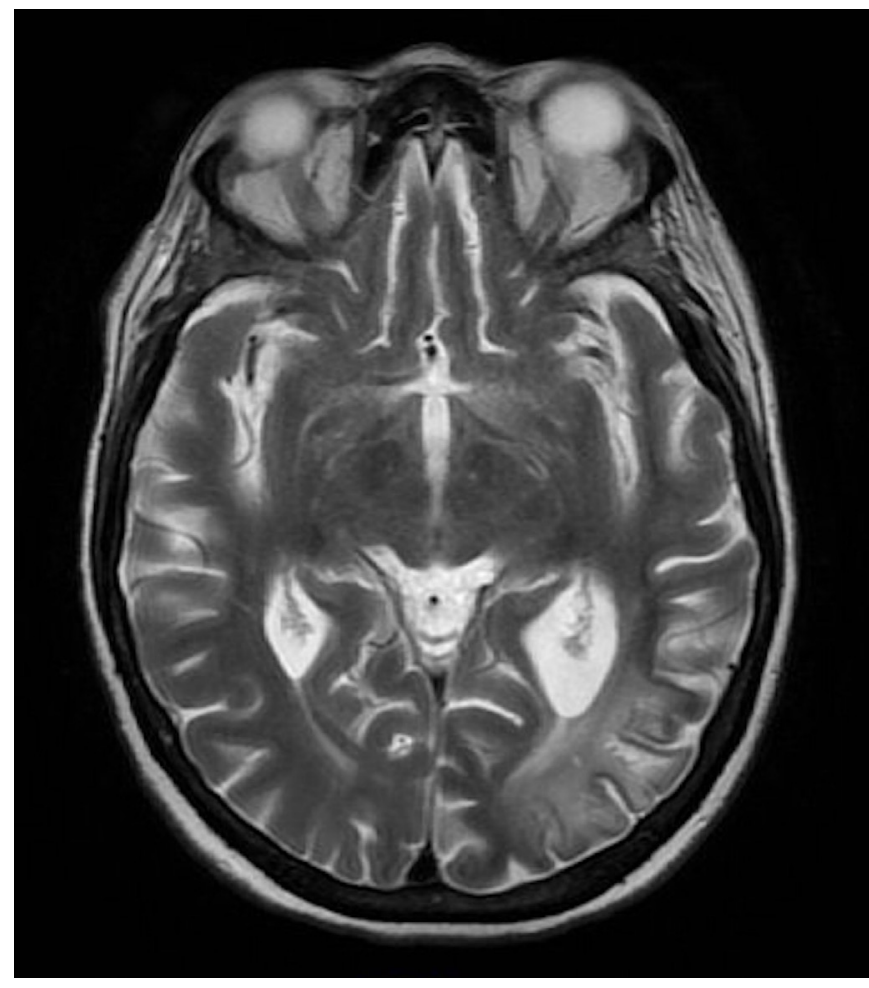

Figure 2 Repeat MRI T2 sequence showing a decrease in the extent of the oedema in the left parietal and temporal lobes when compared with the previous scan. 
months, she had been admitted once with a pneumonia and twice with NOE which had required treatment with intravenous antibiotics and surgical debridement of the left ear. NOE has been described as progressive osteomyelitis of the temporal bone, and is associated with significant morbidity and also mortality (up to $15 \%)$. It occurs in patients who are immunocompromised due to any cause, diabetes mellitus being the most common cause. The prevalence of diabetes ranges from about $65 \%$ to $100 \%$ in patients with NOE. Other conditions that may predispose to NOE include HIV/AIDS, chemotherapy, leukaemia, lymphoma, splenectomy, neoplasia and renal transplantation. ${ }^{8}$ In this case, NOE might therefore be a marker of immunosuppression, most likely secondary to uncontrolled diabetes.

Second, the patient had a significant history of critical illness. During her previous admission for NOE, the patient had to be admitted to the intensive care unit twice, after developing cardiogenic pulmonary oedema on both occasions. Interestingly, a number of studies ${ }^{9-13}$ have consistently shown that CMV infection can occur in immune-competent critically ill surgical, sepsis or burn patients. Furthermore, CMV infection has been associated with higher mortality, prolonged mechanical ventilation and longer hospital stay, although it is not clear whether such relationship describes worse outcomes secondary to CMV infection, or whether CMV infection is a simply a marker for severe disease. ${ }^{9}$

Primary CMV infection usually occurs during childhood and adolescence; the virus subsequently establishes itself in mononuclear cells giving rise to latent infection and a seropositive state with positive anti-CMV IgG antibodies. In most cases, CMV infection occurs as a result of reactivation of latent CMV, although reinfection with an exogenous strain is also possible. The distinction between scenarios is difficult in clinical practice. Osawa et al show that CMV-seronegative critically ill patients tend not to develop CMV infections . ${ }^{12}$ Therefore, this suggests that reactivation of CMV is the more likely cause for CMV

\section{Learning points}

- A viral PCR panel including cytomegalovirus (CMV) PCR may be worthwhile in patients presenting a clinical and radiological picture consistent with viral encephalitis.

- Central nervous system CMV infection can occur with positive cerebrospinal fluid CMV PCR and concurrent negative serum CMV PCR.

- Malignant necrotising otitis externa may be considered a marker of immunosuppression in patients with no other 'classical' causes for immunosuppression such as HIV/AIDS and immunosuppressive therapy.

- Critical illness may be sufficient to cause CMV reactivation in patients with latent infection. CMV infection must therefore be borne in mind in patients with a history of critical illness presenting with organ dysfunction, including an encephalitic picture. infections, and it has been reported that such infection may occur in up to $36 \%$ of critically ill intensive therapy unit (ITU) patients who are otherwise immune competent.$^{12}$ Sepsis has been reported to be one of the most significant triggering events for CMV infection in ITU patients. Furthermore, 31\%-42\% of hospitalised patients with CMV infection may have organ involvement or life-threatening CMV reported. Heininger et al showed that $10 \%$ of those with CMV infection developed severe infection, such as pneumonitis and encephalitis.${ }^{13}$ With anti-CMV IgG resulting positive in our patient, it is reasonable to believe that physiological stress related to critical illness might have driven CMV reactivation, giving rise to CMV encephalitis, although infection with a new CMV strain cannot be excluded.

Acknowledgements Dr Norbert Vella was the patient's caring consultant Neurologist. Dr Charmaine Chircop was also one of the patient's caring neurologists.

Contributors SM was involved with clinical care of the patient, case write-up and literature review. RG was involved with clinical care of the patient, and critically reviewed the case report.

Funding The authors have not declared a specific grant for this research from any funding agency in the public, commercial or not-for-profit sectors.

Competing interests None declared.

Patient consent Next of kin consent obtained.

Provenance and peer review Not commissioned; externally peer reviewed.

\section{REFERENCES}

1 Ross S A, Novak Z, Pati S, et al. Overview of the diagnosis of cytomegalovirus infection. Infectious Disorders-Drug Targets 2011;11:466-74.

2 Parisi SG, Basso M, Del Vecchio C, et al. Viral infections of the central nervous system in elderly patients: a retrospective study. Int J Infect Dis 2016;44:8-10.

3 Tunkel AR, Glaser CA, Bloch KC, et al. The management of encephalitis: clinical practice guidelines by the Infectious Diseases Society of America. Clin Infect Dis 2008:47:303-27.

4 Trentalange A, Calcagno A, Raviolo S, et al. Cytomegalovirus central nervous system compartmentalization in a patient presenting with AIDS. Antivir Ther 2015:20:357-9.

5 Prösch S, Schielke E, Reip A, et al. Human cytomegalovirus (HCMV) encephalitis in an immunocompetent young person and diagnostic reliability of HCMV DNA PCR using cerebrospinal fluid of nonimmunosuppressed patients. J Clin Microbiol 1998;36:3636-40.

6 Phillips CA, Fanning WL, Gump DW, et al. Cytomegalovirus encephalitis in immunologically normal adults. Successful treatment with vidarabine. JAMA 1977;238:2299-300.

7 Pantoni L, Inzitari D, Colao MG, et al. Cytomegalovirus encephalitis in a nonimmunocompromised patient: CSF diagnosis by in situ hybridization cells. Acta Neurol Scand 1991;84:56-8.

8 Carfrae MJ, Kesser BW. Malignant otitis externa. Otolaryngol Clin North Am 2008;41:537-49.

9 Al-Omari A, Aljamaan F, Alhazzani W, et al. Cytomegalovirus infection in immunocompetent critically ill adults: literature review. Ann Intensive Care 2016;6:110.

10 Frantzeskaki FG, Karampi ES, Kottaridi C, et al. Cytomegalovirus reactivation in a general, nonimmunosuppressed intensive care unit population: incidence, risk factors, associations with organ dysfunction, and inflammatory biomarkers. J Crit Care 2015:30:276-81.

11 Limaye AP, Kirby KA, Rubenfeld GD, et al. Cytomegalovirus reactivation in critically ill immunocompetent patients. JAMA 2008;300:413-22.

12 Osawa R, Singh N. Cytomegalovirus infection in critically ill patients: a systematic review. Crit Care 2009;13:R68.

13 Heininger A, Jahn G, Engel C, et al. Human cytomegalovirus infections in nonimmunosuppressed critically ill patients. Crit Care Med 2001;29:541-7. 


\section{Unusual association of diseases/symptoms}

Copyright 2018 BMJ Publishing Group. All rights reserved. For permission to reuse any of this content visit http://group.bmj.com/group/rights-licensing/permissions.

BMJ Case Report Fellows may re-use this article for personal use and teaching without any further permission.

Become a Fellow of BMJ Case Reports today and you can:

- Submit as many cases as you like

- Enjoy fast sympathetic peer review and rapid publication of accepted articles

- Access all the published articles

- Re-use any of the published material for personal use and teaching without further permission

For information on Institutional Fellowships contact consortiasales@bmjgroup.com

Visit casereports.bmj.com for more articles like this and to become a Fellow 